\title{
DIFICULDADES NA TRADUÇÃO LITERÁRIA JAPONÊS-PORTUGUÊS
}

\section{DIFFICULTIES IN JAPANESE-PORTUGUESE LITERARY TRANSLATION}

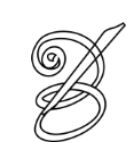

\author{
Michele Eduarda Brasil de SÁ ${ }^{1}$ \\ Doutorada em Letras - Letras Clássicas \\ Professora da Universidade de Brasília \\ Brasília, Distrito Federal, Brasil \\ michedu@gmail.com
}

\begin{abstract}
Resumo: O presente trabalho tem por objetivo analisar dificuldades peculiares à tradução direta do japonês para o português, mais especificamente no que diz respeito ao texto literário. Serão destacados alguns aspectos no que tende a ser considerado como de difícil tradução para a língua portuguesa (onomatopeias, expressões de tratamento, verbos compostos), sendo tais aspectos ilustrados através de excertos de duas obras da literatura japonesa já traduzidas e publicadas para o português: Rashômon, de Akutagawa Ryûnosuke, traduzida em "Rashômon e outros contos" por Marilena Hashimoto Cordaro e Junko Ota, e Wagahai wa neko de aru, de Natsume Sôseki, traduzida como "Eu sou um gato" por Jefferson José Teixeira.
\end{abstract}

Palavras-chave: Tradução; Língua Japonesa; Literatura Japonesa.

Abstract: This study aims to analyze peculiar difficulties in Japanese-Portuguese translation, specifically with regard to the literary text. Some aspects of Japanese language will be highlighted in what is generally regarded as difficult to translate into Portuguese (onomatopoeia, expressions of treatment, compound verbs), and such aspects will be illustrated by excerpts of two Japanese literature works already translated and published Portuguese: Akutagawa Ryûnosuke's Rashômon, translated "Rashômon e outros contos" by Marilena Hashimoto Cordaro and Junko Ota, and Natsume Sôseki's Wagahai wa neko de aru, translated "Eu sou um gato” by Jefferson José Teixeira.

Keywords: Translation; Japanese Language; Japanese Literature.

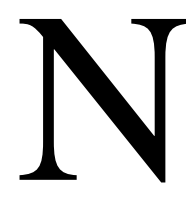

atsume Sôseki, um dos nomes mais famosos da prosa japonesa, morou na Inglaterra entre 1900 e 1903, onde estudou língua e literatura inglesa. ${ }^{2}$ Diz-se que certa vez Sôseki perguntou a seus alunos qual seria a tradução da frase "I love you" para o japonês (KONDO, 2006, p. 182). Como ninguém apresentou uma resposta satisfatória, o próprio professor replicou: Kyô wa tsuki ga kirei desu ne - em tradução literal, "A lua está bela hoje, não?" 3

A partir deste referencial quase anedótico, bastante conhecido para quem trabalha com a tradução direta da língua japonesa, é possível desenvolver outros comentários a respeito das dificuldades encontradas no percurso - a começar pela própria vagueza do discurso japonês, que não deve ser considerada um demérito, mas uma característica própria da língua japonesa. Se mesmo entre português e inglês, por exemplo, que são duas línguas da mesma família 
(indo-europeia), há uma grande distância, quanto mais entre o japonês (da família japônica) e estas duas línguas. Mesmo entre línguas próximas, não parece possível alcançar o ideal proposto em 1791 por Lord Woodhouselee: o de que o estilo em uma tradução deve ter as mesmas características do original (SEIDENSTICKER, 1989, p. 143). Tratando-se de línguas mais distantes (como o inglês e o japonês, com as quais trabalha Seidensticker, ou o português e o japonês, objeto do presente artigo), fica menos realizável este ideal.

Já desde a época do primeiro contato entre japoneses e portugueses, no século XVI, apesar do notável trabalho dos jesuítas, não se pôde evitar que esbarrassem em problemas de tradução, como era de se esperar em um contexto como este (JANEIRA, 1998, p. 147). De início, percebeu-se logo a dificuldade em encontrar uma palavra que traduzisse "Deus" para o japonês. O jesuíta Francisco Xavier primeiro traduziu "Deus" como Dainichi, nome de um dos Budas, mas não tardou a descobrir que este nome queria dizer "Grande Sol”. Começou então a pregar contra Dainichi e traduziu "Deus" como Kami, que significa "ser superior", mas que é a mesma palavra usada até hoje para os milhões de deuses do xintoísmo.

No livro "Rashômon e outros contos", de autoria de Akutagawa Ryûnosuke e 82 traduzido por Marilena Hashimoto Cordaro e Junko Ota, publicado em 2008, percebemos o tratamento com o vocabulário religioso no conto "O mártir", tanto da parte do autor como das tradutoras. No original, encontram-se destacadas palavras como Ekereshiya, Haraiso e Deusu, com a tradução dos termos entre parênteses logo a seguir; na tradução para o português, quando necessário, é colocada, entre colchetes, a tradução para o português da palavra em japonês cuja transliteração foi mantida:

去んぬる頃、日本長崎の「さんた・るちや」と申す「えけれし や」( 寺院)に、「ろおれんぞ」と申すこの国の少年がござつた。 これは或年御降誕の祭の夜、その「えけれしや」の戸口に、餓忍 疲れてうち伏して居つたを、参詣の奉教人衆が介抱し、それより伴 天連の憐みにて、寺中に養はれる事となつたげでござるが、何故か その身の素性を問へば、故郷は「はらいそ」(天国 ) 父の名は「で うす」(天主 ) などと、何時も事もなげな笑に紛らいて、とんと まことは明した事もござない。

Havia naquela época, numa Ekereshiya [igreja] chamada Santa Lúcia, em Nagasaki, no Japão, um rapaz nativo daquele país que tinha por nome Lorenzo. Haviam-no encontrado na noite da festa da Natividade, prostrado de fome e de fadiga diante do 
portão da Ekereshiya. Os fiéis que ali iam rezar o socorreram e o padre, tomado de piedade, resolveu adotá-lo na igreja. Mas, coisa curiosa, cada vez que lhe perguntavam sobre sua origem, nunca esclarecia a verdade e, rindo com naturalidade, dizia que sua terra natal era Haraiso [Paraíso] e que o nome de seu pai era Deusu (A.R., "Rashômon e outros contos", 2008, p. 71-72).

Apesar de ser "gramaticalmente uma das línguas mais simples do mundo", segundo Seidensticker (1989, p. 144), o japonês possui algumas sutilezas que colocam o tradutor diante de escolhas difíceis: optar por se prender mais ao original (assumindo o risco de tornálo inapetente na língua-alvo), ou por adotar uma postura mais distante e criativa (com o perigo de parecer abusar de sua liberdade). Para este estudo, escolhemos três sutilezas bastante comuns no japonês (onomatopeias, expressões de tratamento e verbos compostos), selecionadas em textos literários, e apresentamos exemplos de traduções para o português, a fim de observar as escolhas feitas pelos tradutores. Observemos as ocorrências uma a uma:

- Onomatopeias - Em japonês, são chamadas de giseigo, representando "o som emitido por uma ação ou a voz dos seres vivos", e gitaigo, expressando "o modo pelo qual uma determinada ação é executada" (MORALES, 2008, p. 25-26). São muito comuns, tanto no texto literário quanto no dia-a-dia.

- Expressões de tratamento - São a "projeção das relações sociais na língua" (MORALES, 2008, p. 197); são principalmente verbos, pronomes, partículas e substantivos específicos utilizados para marcar em um enunciado a posição social dos interlocutores.

- Verbos compostos - Embora pareça algo corriqueiro, já que verbos compostos existem em outras línguas, há algumas situações de uso na língua japonesa que geram dificuldades para que sejam traduzidos, por exemplo, para a língua portuguesa. Quando no composto o primeiro verbo é o principal e o segundo tem acepção basicamente aspectual ou modal (como nas locuções verbais "começar a fazer", “continuar a fazer", “conseguir fazer”), geralmente não há problemas (MORALES, 2008, p. 81-97). A dificuldade está em traduzir verbos compostos em que o peso semântico de ambos os verbos seja o mesmo.

A fim de melhor esclarecer os três tipos de ocorrências mencionados, apresentaremos alguns excertos. O primeiro deles, de tradução de Marilena Hashimoto Cordaro e Junko Ota, expõe duas situações: 


\section{その代りまた鴉がどこからか、たくさん集って来た。昼間見ると、 その鴉が何羽となく輪を描いて、高い鵖尾のまわりを啼きながら、 飛びまわっている。}

Corvos começaram então a se juntar em bandos, vindos sabe-se lá de onde. Durante o dia, inumeráveis, eles descreviam círculos e grasnavam ao redor da alta cumeeira (A.R., "Rashômon e outros contos", 2008, p. 28).

A primeira situação é a de um verbo principal com um verbo auxiliar: atsumatte kita (de atsumaru, "juntar-se", e kuru, "vir"). ${ }^{4}$ A tradução, de Cordaro e Ota, de atsumatte kita para o português foi "começaram a se juntar" - que não deve ser confundido com "vieram juntar-se", que proporcionaria, em português, uma noção de finalidade, enquanto que em japonês os verbos em te kita demonstram uma ação contínua a partir de determinado ponto. No entanto, Cordaro e Ota, além de conservarem esta nuance (“começar a se juntar"), 84 mantendo a ideia de uma ação em decurso, também adicionaram o adjetivo "vindos", resgatando o significado do verbo kuru quando autônomo na oração (“vir").

O real desafio, porém, está em situações como a dos verbos a seguir: tobimawatteiru, de tobu ("voar") e mawaru ("girar"), cujos valores semânticos têm o mesmo peso. Neste exemplo, é difícil escolher entre traduzir por "voavam girando" ou "giravam voando". A escolha das tradutoras Cordaro e Ota foi traduzir a expressão utilizando um verbo só: “descreviam círculos”. Trata-se de uma escolha feita com astúcia, pois a expressão utilizada, além de fugir da polêmica sobre qual verbo deveria ser colocado em primeiro plano, dá conta perfeitamente do que a expressão tobimawatteiru significa: fazer movimentos circulares no céu.

Observemos as primeiras palavras em uma das obras mais conhecidas de Natsume Sôseki, Wagahai wa neko de aru, publicada em 1905, traduzida para o português por Jefferson José Teixeira, publicada em 2008. O título equivale à primeira frase do livro:

\footnotetext{
我輩は猫である。名前はまだ無い。どこで生まれたかとん と見当がつかぬ。何でも薄暗いじめじめしたところでニャ 一ニャー泣いていた事だけは記憶している。
} 
Eu sou um gato. Ainda não tenho nome. Não faço a mínima ideia de onde nasci. Guardo apenas a lembrança de miar num local completamente sombrio, úmido e pegajoso (N.S., "Eu sou um gato", 2008, p. 11).

O pronome pessoal utilizado por Sôseki para o seu narrador em primeira pessoa é wagahai (我輩), de uso restrito a pessoas de alta posição hierárquica e de certo matiz de arrogância. Usar este pronome de primeira pessoa em japonês, e não outro (como watashi, boku, ore, por exemplo), já revela a posição de superioridade assumida pelo gato-narrador e sua opinião sobre si mesmo e o mundo em que vive. Em português, porém, o referencial de tratamento que este pronome encerra não pode ser expresso pelo nosso único pronome de primeira pessoa “eu”. Por isso, a solução encontrada pelo tradutor Jefferson José Teixeira foi a inserção de nota de rodapé explicativa. ${ }^{5}$

Na sequência, há duas ocorrências de onomatopeias. A última delas, nya nya (ニャー ニヤ一), representa o miado de um gato, daí nya nya naiteita ter sido traduzido simplesmente por "miar" ("chorar fazendo nya nya", em tradução literal). Quanto às vozes de animais, não há o que elucubrar, a opção mais óbvia é pesquisar no dicionário o verbo correspondente, em se tratando de algum animal menos comum. Porém, as soluções tradutórias para a primeira onomatopeia do trecho acima, jime jime (じめじめ), não são tão simples quanto se poderia pensar, pois dificilmente poderia ser substituída por outra onomatopeia em português. A onomatopeia jime jime (じめじめ) denota o som de um objeto grudento, pegajoso. Contudo, a opção que geralmente satisfaz é a de substituir uma onomatopeia como esta por um advérbio ou por um adjetivo: como pudemos observar no trecho, o tradutor optou por inserir adjetivos "num local completamente sombrio, úmido e pegajoso".

Prosseguindo com Sôseki, vejamos um trecho que corresponde a uma passagem de um poema lido por um dos personagens (o professor, dono do gato).

「大和魂はどんなものかと聞いたら、大和魂さと答えて行 き過ぎた。五六間行ってからエヘンと云う声が聞こえた」 
"Mas ao lhes perguntar

'O que é o Espírito de Yamato?'

a pessoa apenas segue seu caminho respondendo:

'É o Espírito de Yamato, ora.'

E após alguns passos,

Eu a ouço limpar a garganta: 'Ahã'."

(N.S., "Eu sou um gato", 2008, p. 247)

O trecho apresenta um verbo composto de difícil tradução: yukisugita, de yuku/iku ("ir") e sugiru ("passar", "ultrapassar"). Não deve ser confundido com a construção sem o ideograma (すぎた), em que o verbo sugiru é traduzido não como verbo, mas como advérbio (“demais"). Unindo as ideias de "ir" e "passar", que se complementam, o tradutor Jefferson José Teixeira optou por "segue seu caminho". Muitas vezes, em situações como estas, não há alternativa. Quanto à onomatopeia (エヘン), ela simplesmente foi mantida pelo seu correspondente em português "ahã".

\section{Considerações finais}

Como acontece em todas as línguas, tanto no processo tradutório quanto na crítica do produto final, isto é, a tradução, nem sempre as escolhas do tradutor são consideradas satisfatórias. Como afirma Seidensticker (1989, p. 153):

\footnotetext{
Sugerir que o japonês é, de uma forma, um tanto intraduzível é convidar um olhar composto de dor e alívio, o olhar de alguém que espera e contudo teme que a chave tenha sido encontrada. Vamos apenas dizer que existem dificuldades e que a tradução, como Allen Tare falou sobre crítica, é para sempre impossível e para sempre necessária. ${ }^{6}$
}

A ocorrência das onomatopeias em japonês é mais frequente do que em português ou inglês, o que certamente afeta o processo tradutório, as escolhas do tradutor e, por fim, o produto final do ato tradutório, a tradução. Traduz-se as onomatopeias comuns em língua japonesa por verbo, advérbio ou adjetivo e, consequentemente, se perde o apelo que se tem no original em japonês. Levando em consideração que, em japonês, até o silêncio tem uma onomatopeia correspondente, a diferença começa a partir da percepção de onomatopeia que existe em cada cultura. 
Mesmo ocorrendo em muitas línguas, os verbos compostos podem gerar certa dificuldade na tradução. Isto porque nem sempre há uma estrutura semelhante paralela entre as línguas, neste caso entre o japonês e o português. Deve-se observar se os verbos possuem o mesmo peso semântico, somente então passa-se à tradução. Se os verbos tiverem significado semelhantes e o mesmo peso, é comum que os verbos compostos em japonês sejam traduzidos por somente um verbo em português.

Quanto às expressões de tratamento, é comum que elas se percam pelo caminho. Não há como dar conta de pronomes, verbos, partículas marcantes da posição social dos interlocutores quando não há tal tipo de complexidade, sutileza, em português. É possível explicar estas nuances por meio de notas, mas parte do bom senso do tradutor saber quando não abusar das notas explicativas. Em determinados textos, a abundância de notas pode deixar o leitor cansado, embora elas tenham o objetivo de elucidar determinadas nuances de difícil percepção.

Apesar das dificuldades aqui apresentadas e de outras tantas não mencionadas, o mercado de tradução de obras japonesas para a língua portuguesa tem experimentado certo crescimento nos últimos anos (YOSHIDA, 2005, p. 273). Manter este crescimento e aumentálo, se possível, depende de enfrentar as dificuldades de tradução para dar ao público lusófono a oportunidade de conhecer a literatura japonesa.

\section{REFERÊNCIAS BIBLIOGRÁFICAS}

AKUTAGAWA. Ryûnosuke, Rashômon e outros contos. Trad. do japonês Marilena Hashimoto Cordaro e Junko Ota. São Paulo: Hedra, 2008.

Rashômon. Disponível em: <http://www.aozora.gr.jp/cards/000879/ files/127_15260.html> Acesso em 03 set.2014.

JANEIRA, A. M. O impacto português sobre a civilização japonesa. Lisboa: Publicações Dom Quixote, 1988.

KONDO, M. Multiple Layers of Meaning-Toward a Deepening of the 'Sense' Theory of Interpreting. Interpretation Studies, n. 6, p. 175-182, 2006.

NATSUME. Soseki, Eu sou um gato. Trad. do japonês e notas Jefferson José Teixeira. 2. ed. São Paulo: Estação Liberdade, 2008.

Wagahai wa neko de aru. Disponível em: < http://www.aozora.gr.jp/cards/000148/ files/789_14547.html > Acesso em 02 out.2014. 
MORALES, L.M. (Org.). Tópicos de gramática da língua japonesa. São Paulo: Fundação Japão, 2011.

SEIDENSTICKER, E. On trying to translate Japanese. In: BIGUENET, J.; SCHULTE, R. (Ed.). The craft of translation. Chicago: The University of Chicago Press, 1989. p. 142-153.

YOSHIDA, Luiza Nana. Literatura Japonesa - Desafios e perspectivas. In: Anais do XVI

Encontro Nacional de Professores Universitários de Língua, Literatura e Cultura Japonesa e III Congresso Internacional de Estudos Japoneses no Brasil: Brasilia-DF: Departamento de Línguas Estrangeiras e Tradução, 2005, p. 273-279.

\footnotetext{
${ }^{1}$ Lattes Michele Eduarda Brasil de Sá: http://lattes.cnpq.br/5764556680061474

${ }^{2}$ Neste trabalho, será adotada a ordem tradicional para as traduções de autores japoneses (primeiro o sobrenome, seguido do nome).

${ }^{3}$ Original em japonês:「今日は月がきれいですね。」(KONDO, 2006, p. 177)

${ }^{4}$ Em japonês, há duas classificações distintas: a de hojo dôshi ("verbos auxiliares") e fukugô dôshi ("verbos compostos"). Em atsumatte kita, o verbo kuru é um verbo auxiliar.

5 "Das muitas formas de dizer eu em japonês, Soseki optou pelo pronome de primeira pessoa "wagahai", cujo uso era restrito a políticos, militares, etc., e se revestia de certa arrogância." (NATSUME, 2008, p. 11)

${ }^{6}$ N.de.T: Nossa tradução para: To suggest that Japanese is, in a way, somewhat untranslatable is to invite a look compounded of pain and relief, the look of one hoping and yet fearing that the key has been found. Let us only say that there are difficulties, and that translation, as Allen Tare said of criticism, is for ever impossible and for ever necessary.
}

ACEITO EM: 30/11/2014

RECEBIDO EM: 31/08/2015 